\title{
Mechanical Properties of UV-Irradiated Low-Density Polyethylene Films Formulated With Carbon Black and Titanium Dioxide
}

\author{
M. A. Salem \\ Physics Department, Faculty of Science \\ Azhar University, Nasr-City, Cairo, Egypt
}

This study reports on the effect of UV-rays on the mechanical properties of low-density polyethylene (LDPE) films pigmented with carbon black and titanium dioxide $\left(\mathrm{TiO}_{2}\right)$ in different formulations. The film samples were submitted to $U V$-soaking with fluorescent lamps for differ ent exposure times and $40{ }^{\circ} \mathrm{C}$. An untreated LDPE film is used for the purpose of comparison. The physico-chemical structural changes in the irradiated films were monitored by retained elongation- and stress-at-break and by Fouriertransform infrared spectrophoto- metric methods. The changes in both film tensile properties at break and in carbonyl groups under UV exposures are discussed. Retained elongation-at-break is found to decrease with exposure time for most studied formulations, except for formulation of $\mathrm{TiO}_{2} /$ carbon black $=0.75$, it increases with exposure time. The results show that the use of both pigments, carbon black and $\mathrm{TiO}_{2}$ in appropriate concentration ratios gives a reliable improvement in the mechanical and physico-chemical properties of LDPE films exposed to UV-radiation. 


\section{Introduction:}

Polymer photo-degradation and stabilization is an extensive field of study. It is well established that photo-oxidation reactions play an important role in the degradation process of the UV-irradiated polymeric materials, and the controlling mechanisms were studied by some authors [1-3]. The physicochemical changes which occur during photo-oxidative reactions are characterized by an increase in the concentration of the oxygen-containing groups such as peroxides, hydroperoxides and also the ketonic carbonyl groups [4]. However, crosslinking and chain secession processes occurring during photo-oxidation in polyethylene are believed to be sources of great importance in causing changes in the mechanical properties of this material [5]. Investigations of linear low-density polyethylene films indicated that there is a slight increase in the degree of crystallinity when exposed to natural weather [6]. It has been shown also that some additives and impurities may catalyze the breaking of polymer chains by a series of UV-initiated free radical reactions [7]. In polyolefins, the effect of UV-rays on the formation of the chemical functional groups and their role in polymer chain-breaking has been reported [8]. The changes in molecular weight of polyethylene films have been studied recently as a function of various environmental aging [9]. Tsuji and Seiki [10] found that alkyl radicals $\left(-\mathrm{CH}_{2}-{ }^{*} \mathrm{CH}-\mathrm{CH}_{3}\right)$ may be formed in LDPE films during $\mathrm{UV}$-irradiation and they reported also that the formation of oxyradicals is possible if the wavelength of the radiation is greater than $300 \mathrm{~nm}$.

The most studied photoactive additives among polymers are the hindered amine light- stabilizers [11], the UV-absorber benzo-phenones [12], low-molecular weight materials [13] and the metal complexes [14]. However, on the practical side photo-stabilization of LDPE films used for outdoor purposes, mainly agriculture, may be achieved by the combination of different additives of antioxidants and UV-stabilizers [15].

Carbon black is widely used for improvement of weatherability of polyolefins because of its ability to act as inner filter for UV-radiation [16, 17]. In addition, the termination of free radicals generated during photo-oxidative reactions may also contribute to the UV-stabilizing effect of the carbon black [18]. Many inorganic pigments such as iron (1) oxides, chromic oxides and titanium dioxides are also widely used as stabilizers in plastic industry [10].

Apparently, study of literature review indicates that there are no reports on the UV-mechanical properties of LDPE films pigmented with both carbon black and titanium dioxide. Then, the present work reports on the tensile properties of UV-irradiated LDPE films pigmented with C.B and $\mathrm{TiO}_{2}$ in 
different formulations. As other authors [19], the retained elongation-at-break is considered to be the significant measured tensile property, which is more sensitive to photo-oxidative processes in LDPE films. Retained stress-at- break is also utilized to compare the experimental results. The changes in the chemical structure of the films during UV-exposures are evaluated by determining the values of the carbonyl index.

\section{Experimental:}

Commercial LDPE films synthesized by Shouman Plastic Co. (New Demiette, Egypt) were used as received from the supplier. The films were produced by using co-extrusion machine at temperatures ranging from 150 to $170{ }^{\circ} \mathrm{C}$ and with thickness of approximately $50 \mu \mathrm{m}$. The films were pigmented with commercial carbon black (FEF) and titanium dioxide $\left(\mathrm{TiO}_{2}\right)$ in different concentrations (wt.\%). A film without additives but processed under the same conditions as the formulated ones was used as blank. The LDPE formulations used in the present study are given in Table (1). From these formulations, samples of $60 \times 30 \mathrm{~mm}$ were cut and used for UV-soakig and mechanical measurements. The UV-irradiation of the samples was carried out using an array of UV fluorescent lamps emitting light in the region from 280 to $320 \mathrm{~nm}$ with a tail extending to $400 \mathrm{~nm}$. The temperature of the samples during UVexposures was $40{ }^{\circ} \mathrm{C}$ and the relative humidity was $35 \%$.

Table (1): LDPE films used for UV-degradation measurements.

\begin{tabular}{|c|c|c|}
\hline Formulation No. & $\begin{array}{c}\text { Carbon black } \\
\text { C.B (wt. \%) }\end{array}$ & $\begin{array}{c}\text { Titanium dioxide } \\
\mathrm{TiO}_{2} \text { (wt. \%) }\end{array}$ \\
\hline$(1)$ & 7 & 2 \\
$(2)$ & 7 & 4 \\
$(3)$ & 7 & 6 \\
$(4)$ & 7 & 8 \\
$(5)$ & 2 & 8 \\
$(6)$ & 4 & 8 \\
PE (unformulated) & 0 & 0 \\
\hline
\end{tabular}

Retained elongation-at-break of LDPE films was computed from the stress-strain graphs, which were obtained by using a testing machine (type LRX, Lloyl Instr.), with a speed of $50 \mathrm{~mm} / \mathrm{min}$ at $20^{\circ} \mathrm{C}$. The computed results are an average of four tests per sample. The retention percent of elongation-atbreak, $E_{b}$, is defined as

$$
E_{b}=\left(E_{o} / E_{t}\right) \times 100
$$


where $E_{o}$ and $E_{t}$ are elongation-at-break for UV-unirradiated and after exposure time, $t$ in hours, for a given sample, respectively. The retained stress-at-break $\left(\mathrm{S}_{\mathrm{o}} / \mathrm{S}_{\mathrm{t}}\right)$ can be also calculated in the same manner.

The infrared transmission spectra of the studied LDPE films were obtained with ATI-Mattson (Genesis series) FTIR spectrophotometer in the region between 400 and $4000 \mathrm{~cm}^{-1}$. Analyzing the data between 1300 and 1800 $\mathrm{cm}^{-1}$ the values of carbonyl index (C.I) were calculated as the ratio of the absorbance (A) at the two wave numbers [20] :

$$
\text { Carbonyl index }(\text { C.I })=\mathrm{A}_{1710} / \mathrm{A}_{1380}
$$

The peak at $1710 \mathrm{~cm}^{-1}$ corresponds to absorption from the presence of carbonyl group, which is a by-product of the oxidation of polyethylene. The band at $1380 \mathrm{~cm}^{-1}$ was taken as reference peak. The values of C.I were used to compare the photo-activity of the different LDPE films.

\section{Results and Discussion:}

The results of the retained elongation-at-break $\left(\mathrm{E}_{0} / \mathrm{E}_{\mathrm{t}}\right)$ as well as the retained stress-at-break $\left(\mathrm{S}_{\mathrm{o}} / \mathrm{S}_{\mathrm{t}}\right)$ for the tested LDPE films at different uvexposure times are presented in Table (2). The retained elongation-at-break for most formulated films shows fristly slight decrease up to exposure times of about $50 \mathrm{~h}$ and then increases again. The variation in $\left(\mathrm{E}_{\mathrm{o}} / \mathrm{E}_{\mathrm{t}}\right)$ with exposure time (t) for samples with constant C.B and different $\mathrm{TiO}_{2}$ content is illustrated in Fig.(1), while that for constant $\mathrm{TiO}_{2}$ and different C.B content is shown in Fig.(2). From Table (2) and Figs.( $1 \& 2)$ it can be seen that in Eqn. (2) $E_{o} / E_{t}>1$ at all exposure times, whereas in other formulations most of the ratios are less than unity. The initial decrease in $\mathrm{E}_{\mathrm{o}} / \mathrm{E}_{\mathrm{t}}$ with exposure time, Fig. (2), may be due to the occurrence of chain scission processes as a result of the photooxidation. However, the increase in $\mathrm{E}_{\mathrm{o}} / \mathrm{E}_{\mathrm{t}}$ with exposure time may be due to crosslink reaction.

The changes in retained stress-at-break $\left(\mathrm{S}_{\mathrm{o}} / \mathrm{S}_{\mathrm{t}}\right)$ with $\mathrm{TiO}_{2} /$ C.B, indicated in Fig.(3), show a drastic change at all exposure times from maximum at $\mathrm{TiO}_{2} /$ C.B $=0.57$ to a minimum at 1.14 . This behaviour suggests that mechanical strength or elasticity of the formulated LDPE films is strongly dependent on the concentration of both C.B and $\mathrm{TiO}_{2}$. Thus, the variations in $\mathrm{E}_{\mathrm{o}} / \mathrm{E}_{\mathrm{t}}$ and $\mathrm{S}_{\mathrm{o}} / \mathrm{S}_{\mathrm{t}}$ may be due to the changes in chain-scission/cross-linking ratio occurring during UV-soaking. However, the mechanisms which govern the photo-oxidation processes in LDPE films are not simple, since there are many factors affect such processes. These include the intensity and energy of UVrays, the impurities, the particle size of the used C.B and the free radicals formed during the synthesis or processing of the films. 

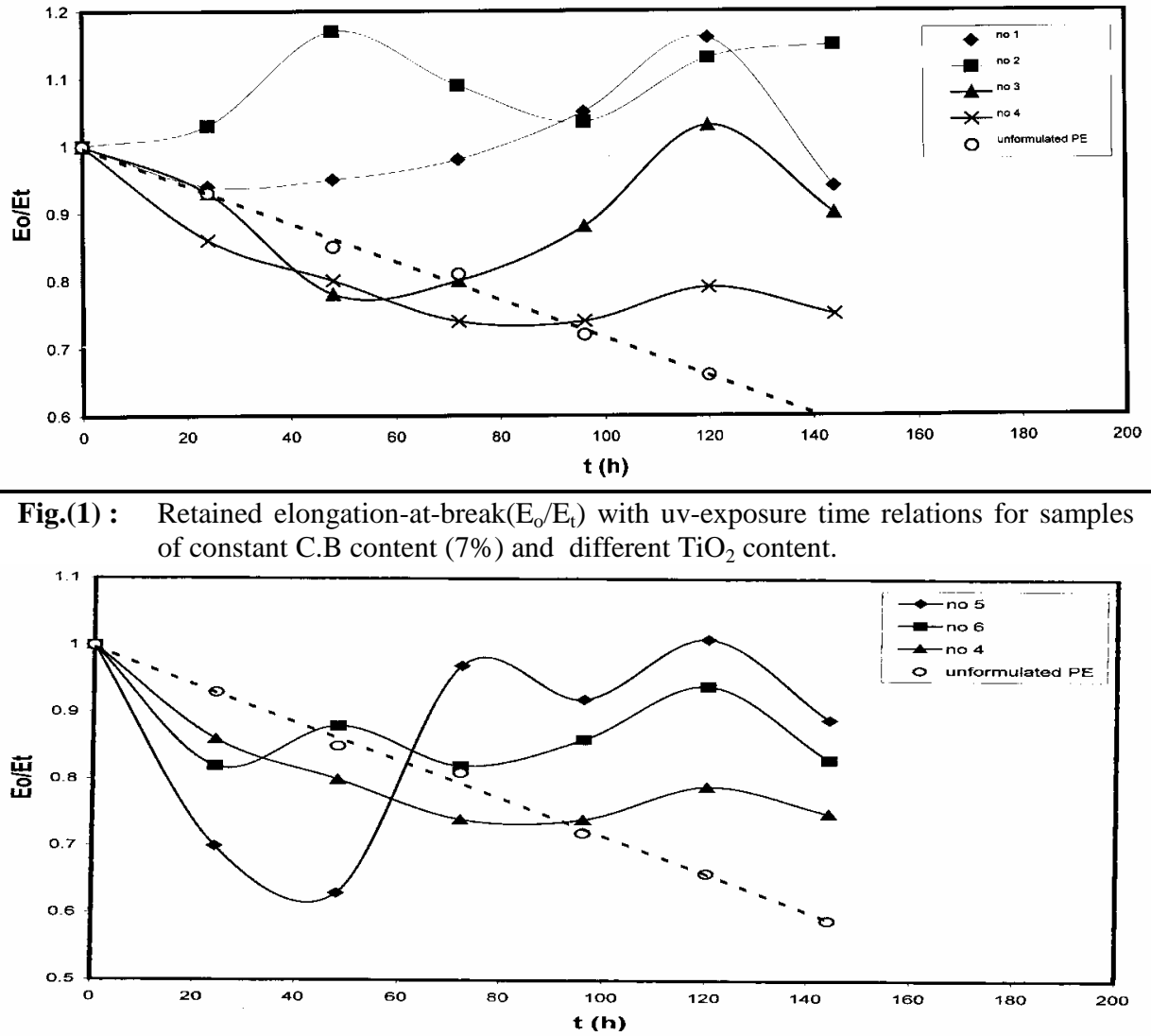

Fig.(2): Retained elongation-at-break $\left(\mathrm{E}_{\mathrm{o}} / \mathrm{E}_{\mathrm{t}}\right)$ with exposure time relations for samples of constant $\mathrm{TiO}_{2}$ content (8\%) and different C.B content.

Table (2): Values of retained elongation-at-break $\left(E_{0} / E_{t}\right)$ and Stress-at-break $\left(S_{0} / S_{t}\right)$, in brackets, at different exposure times.

\begin{tabular}{|c|lllllll|}
\hline Formul. No. & \multicolumn{7}{|c|}{ Exposure time, t(h) } \\
& 0 & 24 & 48 & 72 & 96 & 120 & 144 \\
\hline$(1)$ & 1 & 0.94 & 0.95 & 0.98 & 1.05 & 1.36 & 0.94 \\
& {$[1]$} & {$[0.90]$} & {$[1.0]$} & {$[1.0]$} & {$[1.11]$} & {$[1.27]$} & {$[0.92]$} \\
$(2)$ & 1 & 1.03 & 1.17 & 1.09 & 1.035 & 1.13 & 1.15 \\
& {$[1]$} & {$[1.04]$} & {$[1.27]$} & {$[1.28]$} & {$[1.29]$} & {$[1.65]$} & {$[1.50]$} \\
$(3)$ & 1 & 0.93 & 0.78 & 0.80 & 0.88 & 1.03 & 0.90 \\
& {$[1]$} & {$[0.83]$} & {$[0.66]$} & {$[0.64]$} & {$[0.77]$} & {$[1.04]$} & {$[0.85]$} \\
$(4)$ & 1 & 0.86 & 0.80 & 0.74 & 0.74 & 0.79 & 0.75 \\
& {$[1]$} & {$[0.80]$} & {$[0.72]$} & {$[0.61]$} & {$[0.61]$} & {$[0.70]$} & {$[0.63]$} \\
$(5)$ & 1 & 0.70 & 0.63 & 0.97 & 0.92 & 1.01 & 0.89 \\
& {$[1]$} & {$[0.48]$} & {$[0.43]$} & {$[0.99]$} & {$[0.86]$} & {$[1.05]$} & {$[0.80]$} \\
& 1 & 0.82 & 0.88 & 0.82 & 0.86 & 0.94 & 0.83 \\
PE (unformulated) & {$[1]$} & {$[0.61]$} & {$[0.66]$} & {$[0.64]$} & {$[0.64]$} & {$[0.82]$} & {$[0.59]$} \\
& 0.93 & 0.85 & 0.81 & 0.72 & 0.66 & 0.59 \\
\hline
\end{tabular}




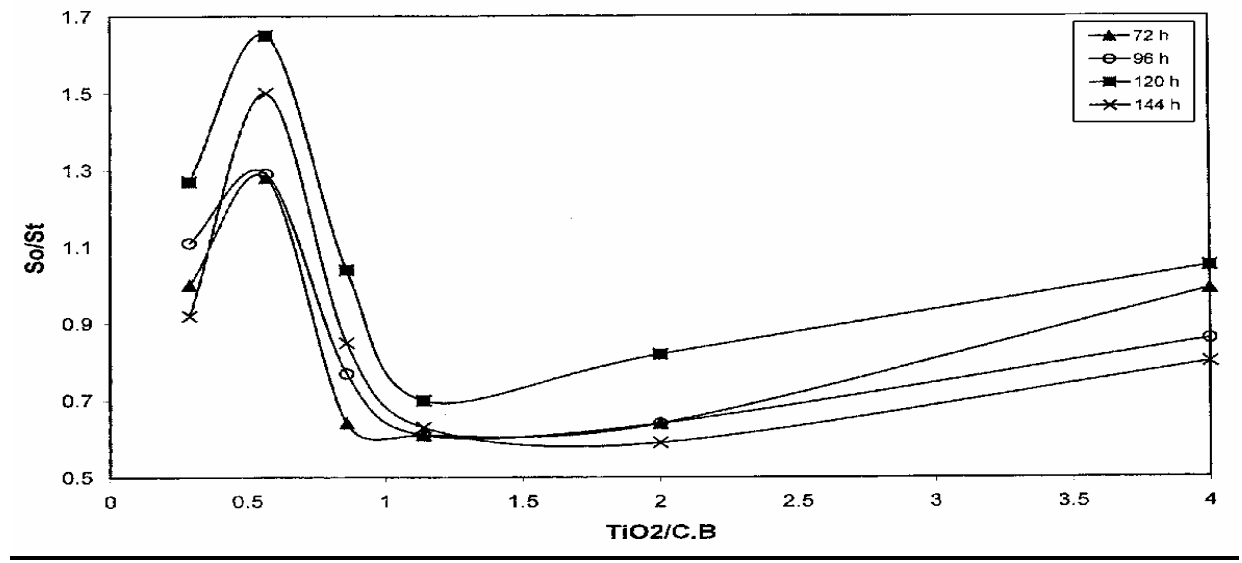

Fig.(3): Retained stress-at-break $\left(\mathrm{S}_{\mathrm{o}} / \mathrm{S}_{\mathrm{t}}\right)$ with $\mathrm{TiO}_{2} /$ C.B ratio .

In comparative studies as the present work, these factors are of less importance. $E_{0} / E_{t}$ which is a measure of the photo-degradation of unformulated LDPE film is found to exhibit a linear dependence on the exposure time, which is similar to that found by other authors $[5,15 \& 20]$. The behaviour of the unformulated film exposed to UV-radiation in air can be attributed to the uptake of oxygen, formation of carbonyl, hydroxyl and vinyl groups; water and carbon oxides [10]. This may be observed from the IR-transmission spectra of this film (at $t=120 \mathrm{~h}$ ), which is shown in Fig.(4). On considering the IR-spectra of the formulated films, at $120 \mathrm{~h}$ exposure time, Fig.(5) and analyzing the data between 1300 and $1800 \mathrm{~cm}^{-1}$, the values of the carbonyl index (C.I) calculated according to Eqn. (2) are quoted in Table(3). Fig.(6) shows that C.I decreases first to minimum with increasing $\left(\mathrm{TiO}_{2} / \mathrm{C} . \mathrm{B}\right)$ to 0.57 then it increases again. From Table (3) it is found that unformulated polyethylene film exhibits the highest value of the C.I (0.43). Figure (3) indicates that $\mathrm{S}_{\mathrm{o}} / \mathrm{S}_{\mathrm{t}}$ increases with slower rate beyond $\mathrm{TiO}_{2} / \mathrm{C} . \mathrm{B}=1.14$ which means that above this ratio the mechanical strength of these films are slightly affected. Thus, the mechanical properties of the formulated LDPE films exposed to UV-rays are strongly dependent on $\mathrm{TiO}_{2} / \mathrm{C} . \mathrm{B}$ ratios. The high efficiency of C.B as photostabilizer for LDPE films is due to its UV- absorptivity and the reaction of the polar groups present on the surface with the free radicals formed in polyethylene [16]. However, the wide application of C.B is only limited by its black colour. On the other side, $\mathrm{TiO}_{2}$ pigment is opaque to UV-rays and acts as a screen by reflecting UV-rays and thereby limits its penetration into the films. Thus, the complementary function of both C.B and $\mathrm{TiO}_{2}$ pigments as photo-stabilizers for LDPE films is an advantageous and therefore, the use of these pigments in proper amounts gives an excellent improvement in the mechanical and physicochemical properties of LDPE films exposed to UV-radiation. 


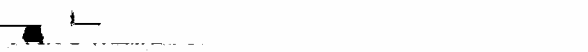

Fig.(4): Infra-red transmission spectra of the unformulated sample at $120 \mathrm{~h}$ exposure time.

Table (3): Values of the carbonyl index (C.I) of LDPE films measured at exposure time of $120 \mathrm{~h}$.

\begin{tabular}{|c|c|}
\hline $\begin{array}{c}\text { Formulation } \\
\text { No. }\end{array}$ & $\begin{array}{c}\text { Carbonyl index } \\
\text { ( C.I) }\end{array}$ \\
\hline$(1)$ & 0.17 \\
$(2)$ & 0.10 \\
$(3)$ & 0.14 \\
$(4)$ & 0.31 \\
$(5)$ & 0.39 \\
$(6)$ & 0.28 \\
PE (unformulated) & 0.43 \\
\hline
\end{tabular}



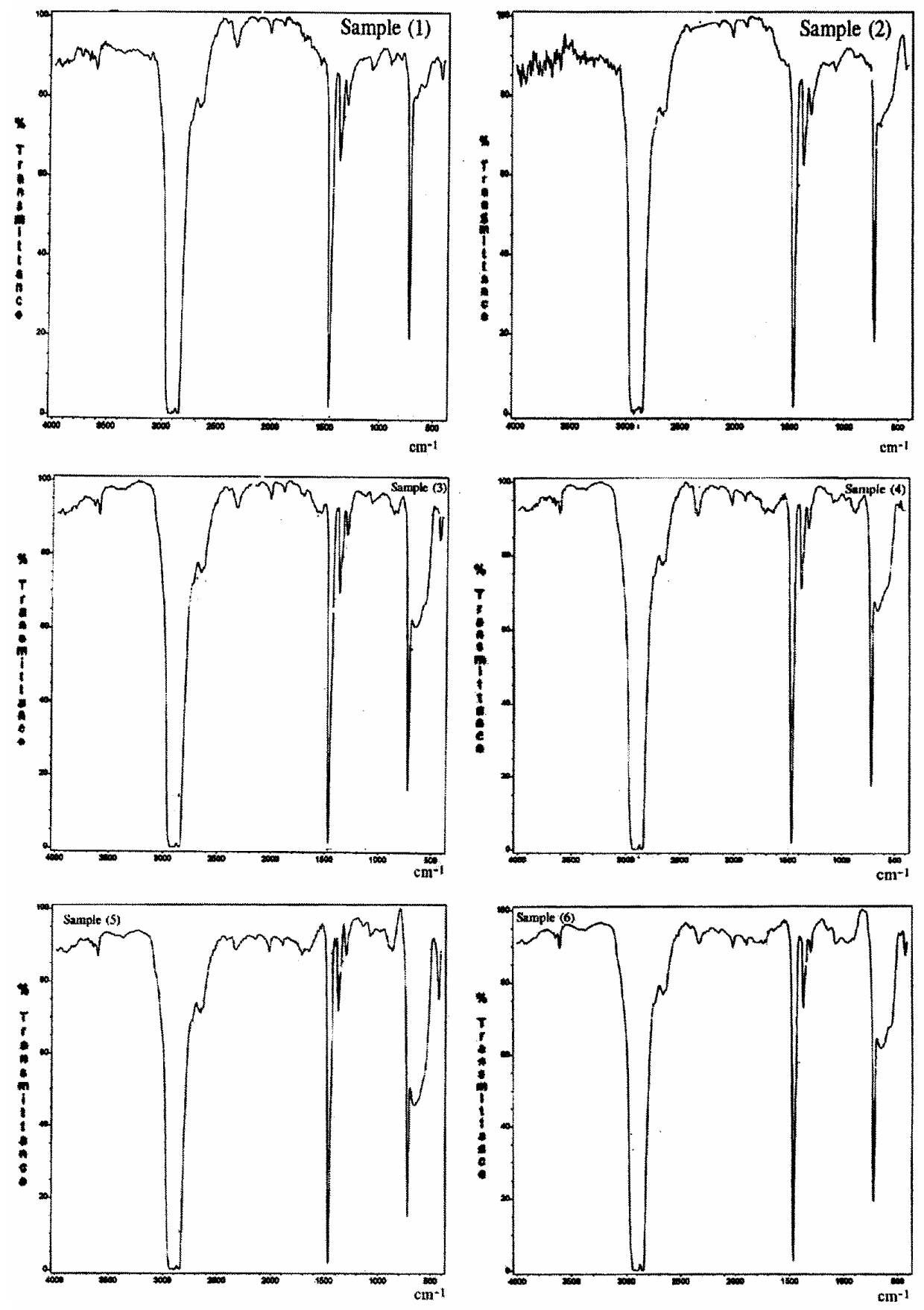

Fig.(5): Infra-red transmission spectra of the unformulated sample at $120 \mathrm{~h}$ exposure time. 


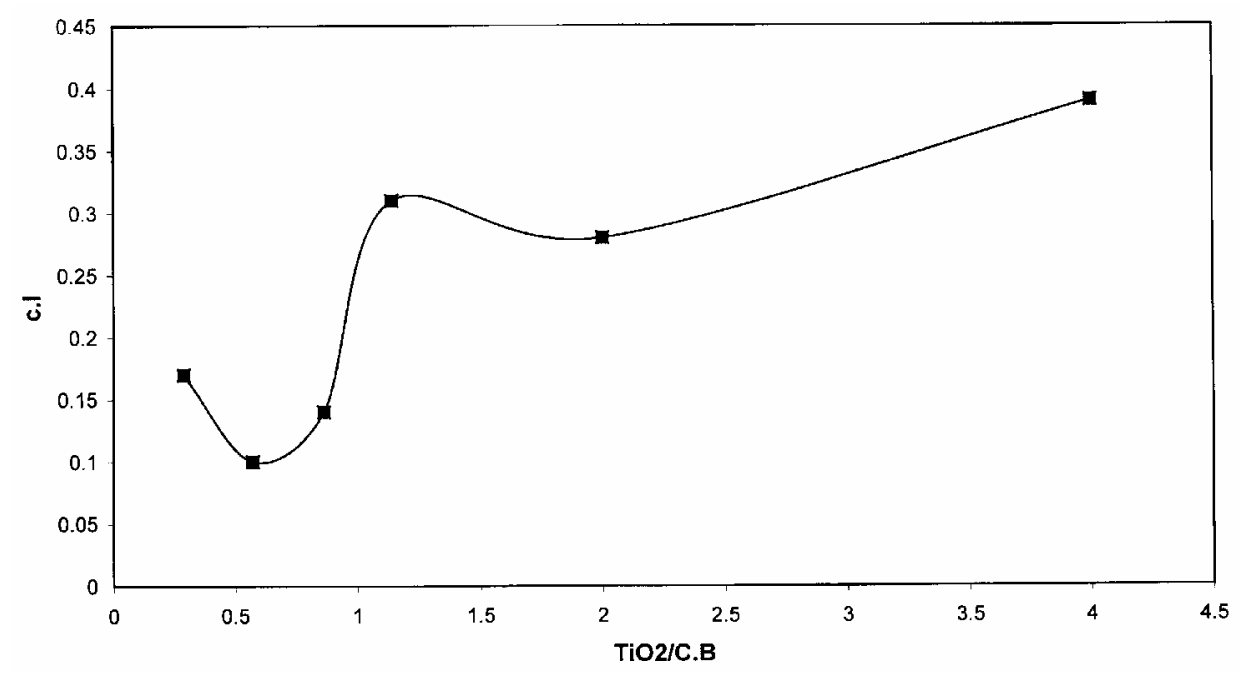

Fig.(6): Dependence of carbonyl index (C.I) on $\mathrm{TiO}_{2} /$ C.B ratio.

\section{Acknowledgment:}

Thanks are due to Shouman Plastics Co., Egypt for technical support, also Prof.Dr. M. Metauh (Petroleum Research Center, Cairo) is warmly thanked for his valuable discussions.

\section{References}

1. W.L., Hawkins, "Polymer Stabilization", John Wiley \&Sons, New York p.1 (1972).

2. G., J. Scott, J. Polym. Sci. Symp., No.57, John Wiley \& Sons, New York p.357 (1976).

3. N. C. Billingham, and Calvert, P.D, "Degradation and Stabilization of Polyolefins", Applied Science Publishers, London, p.1 (1983).

4. F., Sitek, Guillet, J.E and Heskins, M., J. Polym. Sci. Symp., No.57, John Wiley \& Sons, New York p.343 (1976).

5. Mingguang, L., Richard, H. and Michael,E., Polym. Deg. Stab., 49, 151 (1995).

6. Qureshi, F.S, Amin, M.B., Maadhah,A.G. and Hamid,S.H., Polym. Plast. Tech. Eng., 28, 649 (1989).

7. Marco,S., Fiorella,P. and Vittorio, C., Coordination Chem. Rev., 125 , 219 (1993).

8. Guillet, J.E., Pure Appl. Chem., 52, 285 (1980).

9. David, C., Trojan, M., Daro,A. and Demarteau, W., Polym. Deg. Stab., 37, 233 (1992). 
10. Ranby,B. and Rabek, J.F., "Photodegradation, Photooxidation and Photostabilization of Polymers", Wiley Interscience. Publications, p.73 and 363 (1975).

11. Kurumada, T., Ohsawa, H.and Yamazaki, T., Polym. Deg. Stab.19, 263 (1987).

12. Chirinos, A.J., Hernandez,P.H. and Allen, N.S., Polym.Deg. Stab. 19, 177 (1987).

13. Thomas, R.H., Polym. News, 15, 54 (1990).

14. Amin, M.U. and Scott, G., Eur. Polym. J., 10, 1019 (1974).

15. Berlanga-Duorte, M.L., Angulo-Sanchez, J.L. and Ganzalez-Cantu, M.C., J. Appl. Polym. Sci., 60, 413 (1996).

16. Horrocks, A.R., Mwila, J., Miraftab, M.Liu, and Chohan, S.S., Polym. Deg. Stab., 65, 25 (1999).

17. Wilson, J.R., Cabot Report, CIM-97-38, August (1997).

18. Funt, J.M., Sifleet, W.L. and Tomme, M., "Carbon Black", $2^{\text {nd }}$ ed. Marcel Dekker Inc., New York p.389 (1993).

19. Scoponi, M., Pradella, F. and Carassiti,V., Coordination Chem. Rev. , 125 (1993) 219.

20. Angulo-Sanchez, J.L., Ortega-Ortiz,H. and Sanchez-Valdes, S., J. Appl. Polym. Sci., 53, 847 (1994). 